\title{
East or west: the energetic cost of being a gray whale and the consequence of losing energy to disturbance
}

\author{
S. Villegas-Amtmann ${ }^{1, *}$, L. K. Schwarz ${ }^{2}$, G. Gailey ${ }^{3}$, O. Sychenko ${ }^{3}$, D. P. Costa ${ }^{1}$ \\ ${ }^{1}$ Ecology and Evolutionary Biology Department, University of California Santa Cruz, Santa Cruz, CA 95060, USA \\ ${ }^{2}$ Institute of Marine Sciences, University of California Santa Cruz, Santa Cruz, CA 95060, USA \\ ${ }^{3}$ Texas A\&M University, Galveston, TX 77553, USA
}

\begin{abstract}
Western gray whales (WGW) Eschrichtius robustus are considered one of the world's most endangered baleen whale populations. Development of oil and gas fields in northeastern Sakhalin, Russia, is a concern, because they overlap with WGW feeding grounds. Some WGW migrate $\sim 10000 \mathrm{~km}$ from feeding grounds around Sakhalin Island (Russia), to breeding grounds in Baja California (BajaC; Mexico) and possibly 6000 km to the South China Sea (China). We developed a WGW female bioenergetics model to examine potential consequences of energy lost from foraging cessation caused by anthropogenic disturbance, and compared it to eastern gray whales (EGW). Energy loss was then linked to potential reductions in reproduction and survival. Mean total energy requirements were 11 and $15 \%$ greater for WGW breeding in BajaC and China, respectively, compared to EGW, due to longer migration distance $(25 \%)$ to BajaC and higher metabolic rates at foraging grounds. However, this difference is minimal for EGW that use the northern extent of their foraging range. On average, WGW breeding in BajaC and China need 9 and $17 \%$ more energy for survival than EGW. Our model predicts that WGW mortality would likely occur at 38 to $40 \%$ annual energetic loss. Long-term yearly energy loss of $<30 \%$ would reduce population growth due to lower reproductive rates. Ongoing yearly energy losses of $>30 \%$ would result in adult female mortality the first year, followed by lower reproductive rates of survivors. Our model suggests that energy losses of $>30 \%$ caused by disturbance should be considered a threshold for concern for this Critically Endangered population.
\end{abstract}

KEY WORDS: Western gray whale - Eschrichtius robustus - Bioenergetics - Disturbance costs · Metabolic rate $\cdot$ Reproductive costs $\cdot$ Migration costs $\cdot$ Foraging costs $\cdot$ Energy loss

\section{INTRODUCTION}

Gray whales Eschrichtius robustus are extant only in the North Pacific, with 2 stocks (western and eastern) considered to be distinct populations based on their different haplotypes (LeDuc et al. 2002, Lang et al. 2011, Bickham et al. 2013). Commercial whaling brought the species to near extinction, but the eastern stock recovered quickly after whaling ended in the mid-1900s, and has possibly reached carrying capacity with 15 000-22 000 individuals (Laake et al.

*Corresponding author: stella.villegas@gmail.com
2009, Punt \& Wade 2010). However, the western stock is considered one of the world's most endangered baleen whale stocks. The International Union for Conservation of Nature (IUCN) listed the western stock as Critically Endangered (Reilly et al. 2008), with only 174-186 non-calf individuals in 2015 (Cooke et al. 2015). Eastern gray whales (EGW) travel $\sim 8000 \mathrm{~km}$ from their summer feeding grounds in the Chukchi and Bering Seas to their winter breeding grounds in Baja California (BajaC), Mexico (Pike 1962). The migration timing, routes, and breed-

() The authors 2017. Open Access under Creative Commons by Attribution Licence. Use, distribution and reproduction are unrestricted. Authors and original publication must be credited. 


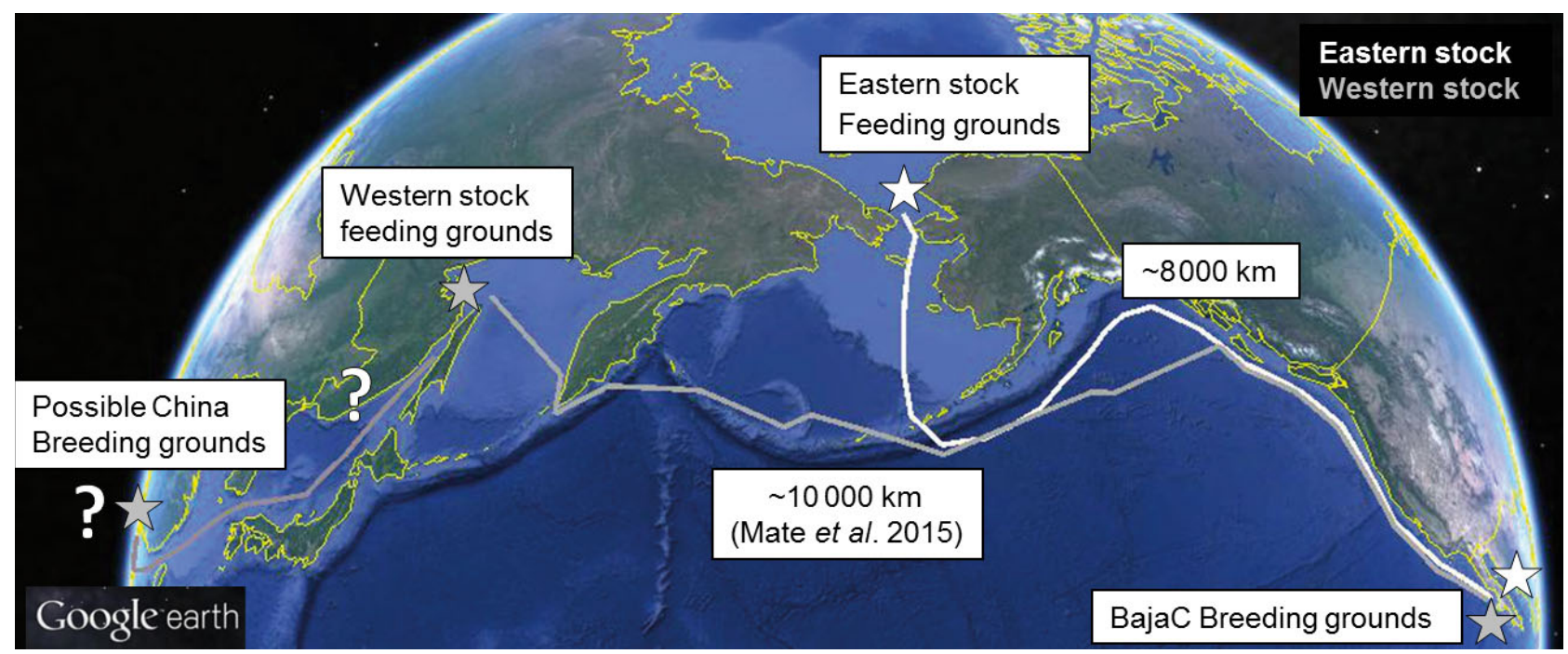

Fig. 1. Known migration routes of eastern and western gray whales Eschrichtius robustus to Baja California, Mexico (BajaC), with estimated distance covered and putative migration route to China. Source: Google Earth, 51 ${ }^{\circ} 52^{\prime} 50.95^{\prime \prime} \mathrm{N}, 1^{\prime} 7^{\circ} 48^{\prime}$ 12.56" W, 13 December 2015

ing grounds of western gray whales (WGW), however, are poorly understood. Their primary feeding habitat is located off the northeastern coast of Sakhalin Island, Russia (Weller et al. 1999, 2002, Tyurneva et al. 2010). Some animals travel $\sim 10000 \mathrm{~km}$ from their summer feeding grounds to BajaC (photo identification and tracking data; Mate et al. 2011, 2015, Weller et al. 2012; Fig. 1). Records from sightings, strandings, and whaling indicate that at least in recent history, WGW occurred in the coastal waters off the Pacific coast of Honshu, Japan (Weller et al. 2008a) and China in the South China Sea (Wang 1984, Zhu 1998). Although gray whales have not been seen in the South China Sea recently, possible calving grounds exist in the coastal waters of Guangdong Province in the Daya Bay and Wailuo Harbor and adjacent waters of the east coast of Hainan Island (Wang 1984), indicating a travel distance of $\sim 6000 \mathrm{~km}$ from their foraging grounds. The possibility of a subset of western stock individuals remaining in the western Pacific year-round has particular implications for conservation and management because the full-time western stock would consist of even fewer than the estimated 174-186 non-calf animals foraging at Sakhalin Island (Bickham et al. 2013, Cooke et al. 2015). However, this full-time western stock has potentially been functionally extinct since the 1930s (Bowen 1974).

The near-shore affinity of gray whales makes them particularly vulnerable to anthropogenic activities. Although hunting may still occur (Brownell \& Kasuya 1999, Baker et al. 2002), the major threats for the western population are indirect mortality (e.g. bycatches and ship strikes) and habitat pollution and degradation (Weller et al. 2002). For over a decade, industrial development in the coastal waters of northeastern Sakhalin, specifically oil and gas development and exploration, has caused considerable concern, especially since the oil and gas fields overlap with critically important feeding habitats for WGW (Blokhin \& Burdin 2001, Gailey et al. 2008). Coastal development and industrial activity (including fisheries activities) pose significant threats to the future survival of WGW (IWC/IUCN Western Gray Whale Conservation plan, Jones et al. 1984, Brownell \& Yablokov 2001, Weller et al. 2008b). Consequently, it is vital to understand how this population might respond to disturbance.

As capital breeders, gray whales must acquire almost all of the energy required for migration and reproduction during a relatively short period of their annual cycle at the foraging grounds (mainly from ampeliscid, pontoporeiid, and anisogamarid amphipods; Rice \& Wolman 1971, Bogoslovskaya et al. 1981, Nerini 1984, Blokhin 1986, Fadeev 2004, 2008, Demchenko et al. 2016). Lactation is one of the most energetically expensive physiological processes in mammals (Hanwell \& Peaker 1977, Williams et al. 2007) and, for gray whales, occurs mostly during their fasting period. Therefore, the energy acquired by a female during this limited foraging period must be sufficient to support her and her offspring throughout the migration from the foraging area to the breeding grounds and back. 
WGW survival rates indicate that non-calf females (1.5 yr and older) are very long-lived, with a median annual survival rate of 0.985 (90\% Bayesian confidence interval 0.977-0.991; Cooke 2010). Under optimal conditions, gray whales are capable of giving birth every other winter (Rice \& Wolman 1971). However, some WGW females observed with a calf at the foraging grounds have subsequently been observed without a calf during 2 or more consecutive years. This indicates an inter-birth interval of 3 or more years, which may account for their slower population growth rate (Sychenko 2011).

A bioenergetics modeling approach was developed to help identify the circumstances under which biologically meaningful population responses to anthropogenic disturbance may occur. The model assumes that a biologically significant disturbance will cause changes in behavior resulting in reductions of net energy intake, compromising maternal condition, leading to reduced fecundity, energy delivery to offspring, offspring survival, and when high enough, increased adult mortality (NRC 2005, Costa 2012, New et al. 2013, 2014). Following that framework, Villegas-Amtmann et al. (2015) created a bioenergetics model for EGW females using a 2 yr reproductive cycle, and identified the demographic consequences of lost energy under possible disturbance scenarios. Disturbance while the female is pregnant is the first potential impact on future gray whale populations. The model assumed that energy required for pregnancy and lactation is acquired during only 1 foraging season, providing the greatest reproductive output when resources are abundant. However, such a scenario is not realistic for persistence of a species if it were to face consistently poor conditions. A longer reproductive cycle (longer inter-calf interval) would allow females to build up the energy needed for reproduction over multiple years and would likely occur when the population approaches carrying capacity. This scenario seems plausible for one of the oldest extant baleen species that has persisted through significant fluctuations in the marine environment (Pyenson \& Lindberg 2011).

We extended the model of Villegas-Amtmann et al. (2015) to calculate WGW energy requirements for a $2+$ yr reproductive cycle and for 2 possible breeding grounds: (1) western Pacific, around Hainan Island in the South China Sea, and (2) eastern Pacific in the lagoons of Baja California, Mexico. We compared energy requirements between EGW and WGW populations and between both WGW breeding sites. Finally, we examined the potential population consequences of lost energy by developing a population model, linking lost energy to reduced reproduction and survival.

\section{METHODS}

We estimated the total energetic requirements for an adult female WGW to survive and migrate from the feeding to the breeding grounds successfully reproducing upon her return (Villegas-Amtmann et al. 2015). We estimated the magnitude of annual energy loss that would affect reproduction, offspring care, and survival. For simplification, whenever 2 values are given for the same variable, the first value refers to those females breeding in BajaC and the second one to females breeding in China.

We used 3 different reproductive conditions for gray whales at the foraging grounds: (A) pregnant females, (B) non-pregnant females without a calf (resting), and (C) non-pregnant females with a calf (lactating) (Fig. 2). Female gray whale energetic demands were parsed into 3 categories: (1) field metabolic rate (FMR), reflecting energy requirements for maintenance at different activity levels and reproductive stages; (2) pregnancy costs; and (3) lactation costs, consisting of calf maintenance or metabolic rate and calf growth costs from $0-6.5$ or 6.6 mo of age (weaning age). Energy requirements for 9 stages were based on the 3 reproductive phases from above: (i) foraging grounds (pregnant), (ii) foraging grounds (non-pregnant), (iii) southbound migration (pregnant), (iv) breeding lagoons (lactating), (v) north-

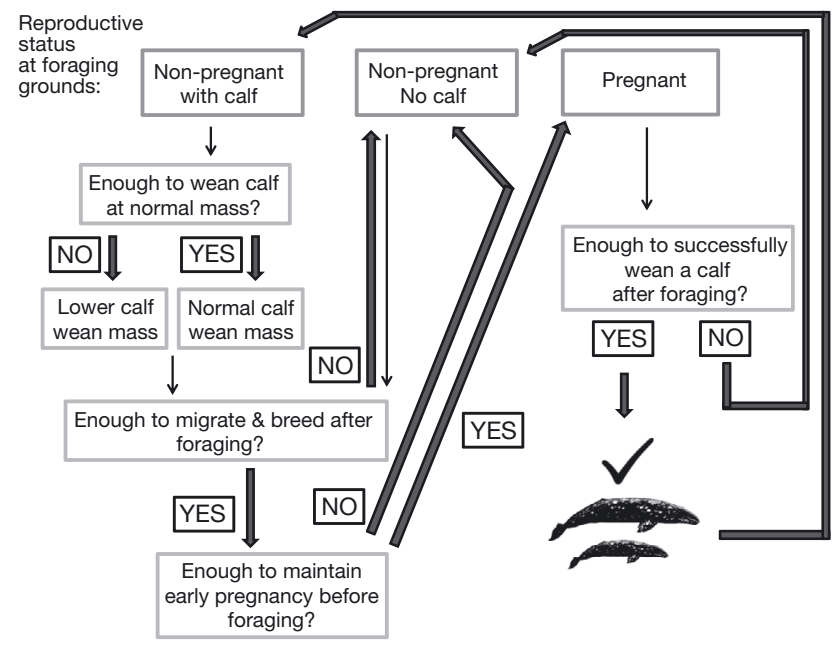

Fig. 2. Female gray whale Eschrichtius robustus 2+ yr breeding cycle. A female with a calf at the foraging grounds will allocate energy to the nearly-weaned calf before storing energy for another pregnancy. Gray whale image with permission from Pieter Folkens 
bound migration (lactating), (vi) foraging grounds (lactating, weaning), (vii) southbound migration (nonpregnant), (viii) breeding lagoons (in estrus), and (ix) northbound migration (newly pregnant).

Data to calculate female gray whale energetic demands were obtained from an extensive literature review. Morphometric data for the WGW population was obtained from the model created for EGW (Rice \& Wolman 1971, Villegas-Amtmann et al. 2015). Timing and duration of female stages were obtained from satellite tracks and behavioral studies of the WGW population at their foraging grounds (Sychenko 2011, Mate et al. 2015), assuming they are migrating from Sakhalin Island, Russia, to BajaC. Developing a bioenergetics model for whales migrating and breeding off the coast of Hainan Island, China, is particularly challenging, as the timing and duration of stages are virtually unknown. We therefore assumed the same migration speed as WGW migrating to BajaC. Lactation duration and respiration rates for females and calves at the foraging grounds were obtained from behavioral data of the WGW population (Sychenko 2011).

We incorporated uncertainty into the model using Monte Carlo sampling to build distributions around each variable with both measurement and process uncertainty whenever possible, instead of using a mean or other point value. Results are presented with $95 \%$ Bayesian credible intervals.

\section{Gray whale female energetic demands}

Female FMR (in MJ) was estimated (Sumich 1986) from respiration rates obtained by visual observation of females during all phases of their reproductive cycle and converted to breaths per day by using a Monte Carlo simulation to reduce uncertainty and provide a more realistic distribution of respiration rate (Table 1). Total metabolic energy expenditure for a given stage $\left(E_{\mathrm{s}}\right)$ in $\mathrm{MJ}$ was calculated using the following relationship:

$$
E_{\mathrm{S}}=0.0200 \cdot \% \mathrm{O}_{2} \cdot T_{\mathrm{s}} \cdot R_{\mathrm{s}} \cdot V_{\mathrm{t}}
$$

where 0.0200 is the amount of heat produced in MJ $\mathrm{I}^{-1} \mathrm{O}_{2}$ consumed, from Kleiber (1961), \% $\mathrm{O}_{2}$ is the oxygen extraction efficiency per breath, $T_{\mathrm{s}}$ the number of days in that stage, $R_{\mathrm{S}}$ is respiration rate in breaths $\mathrm{d}^{-1}$, and $V_{\mathrm{t}}$ is tidal lung volume in 1 (Villegas-Amtmann et al. 2015).

Calf FMR was similarly estimated for each of 3 preweaning calf stages (used to estimate lactation costs) for BajaC calving grounds: breeding lagoons (0-
2.1 mo old), northbound migration (2.1-5.4 mo old), and foraging grounds (5.4-6.6 mo old) and for China calving grounds: breeding lagoons (0-3.4 mo old), northbound migration (3.4-5.3 mo old), and foraging grounds (5.3-6.5 mo old). For further details, see the Supplement at www.int-res.com/articles/suppl/n034 p167_supp.pdf.

It is difficult to predict how long a gray whale mother would stay in the putative breeding lagoons off China. Given the shorter migration time required to reach China, WGW would have more time to spend in or near the breeding grounds, or they could slow their migration speed. How or where WGW spend this extra time is completely unknown, but has significant effects on the model, as the respiration rate, and therefore metabolic rate, of gray whales is higher in the breeding lagoons of BajaC than during the migration. Thus, if we assume females are spending more time in the breeding grounds, using EGW lagoon data, WGW breeding in lagoons off China would expend more energy than WGW breeding in BajaC. This is because WGW females breeding in $\mathrm{BajaC}$ spend more time migrating, which is energetically less costly than spending time in the breeding lagoons. While we have no explanation for why gray whales at the breeding lagoons have higher respiration rates than migrating animals, or whether this is specific to conditions in BajaC, these data were empirically determined. We therefore modeled 2 scenarios. First, we assumed that WGW remain in the China breeding grounds as long as possible, that is $124 \mathrm{~d}$. Second, they remain in the breeding grounds for the same time as WGW females migrating to BajaC, and instead spend additional time outside of the breeding grounds at the same metabolic rate as migrating WGW females.

Pregnancy costs were calculated as in VillegasAmtmann et al. (2015) as the sum of the heat increment of gestation $\left(H_{\mathrm{g}}\right)$ and the energy contained in the newborn calf from the relative contribution of lipid and protein to its mass and associated tissues. We assumed the full-term fetus was $80.7 \pm 2.5 \%$ of the total cost of reproductive tissue (Anderson \& Fedak 1987, Kurta \& Kunz 1987, Blaxter 1989) and a lipid energy density of $39.7 \mathrm{MJ} \mathrm{kg}^{-1}$ and protein energy density of $23.8 \mathrm{MJ} \mathrm{kg}^{-1}$ (Kleiber 1961). $H_{\mathrm{g}}$ in MJ was estimated using the relationship between mass ( $M$ in $\mathrm{kg}$ ) and energy developed by Brody (1945) without uncertainty:

$$
H_{\mathrm{g}}=18.41 \times 10^{6} \cdot M^{1.2}
$$

Lactation costs were calculated as the sum of calf FMR and calf growth costs until weaned at $6.5 \mathrm{mo}$ 


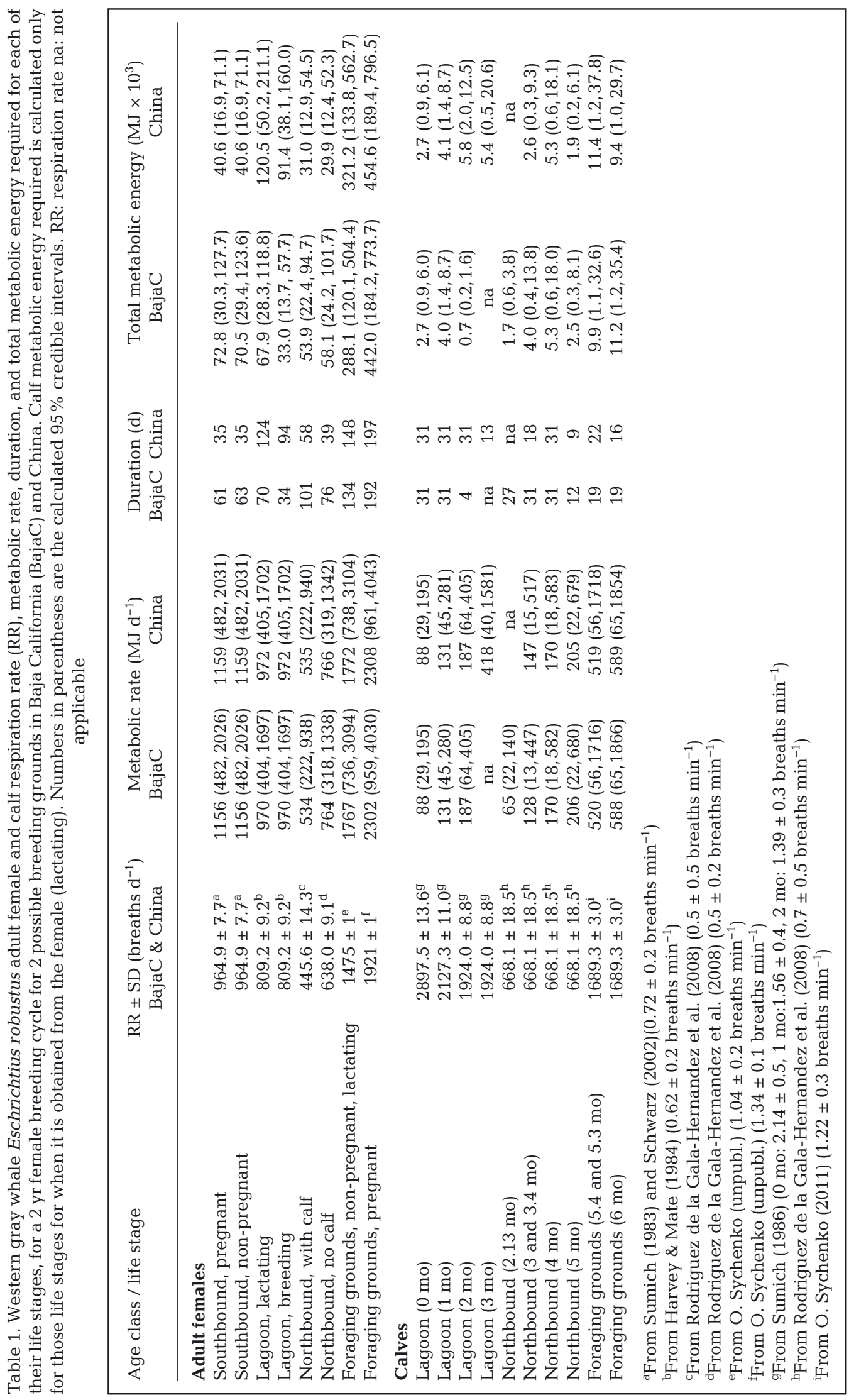


(China) and 6.6 mo old (BajaC) (Villegas-Amtmann et al. 2015). The longer migration from BajaC results in a slightly shorter foraging period for BajaC breeding animals (192 vs. 197). The estimated birth date is the same for both breeding sites; therefore, calves from BajaC arrive at the foraging grounds at a slightly older age. Because wean date is based on the number of days since arrival at the foraging grounds (Sychenko 2011), China breeding animals, which arrive earlier, wean earlier (roughly $3 \mathrm{~d}$ ). Based on capital-breeding northern elephant seals (Costa et al. 1986), we assumed production of milk had a negligible cost (in addition to the calf's metabolic rate and growth costs) and we assumed that all energy from milk was assimilated (Costa 2009). Energy needed for total calf growth from 0-6.6 (BajaC breeding ground) or 0-6.5 (China breeding ground) months old, was calculated as the difference between calf caloric value at birth and at 6.6 or 6.5 mo old.

\section{Model assumptions}

Based on available literature, we made the following model assumptions: (1) Under non-disturbance scenarios, females have the ability to acquire all of the energy necessary for pregnancy and lactation during the foraging period in which they are pregnant. (2) Calves must nurse at least until they reach the foraging grounds to survive. (3) If females lack sufficient energy reserves to complete the southward migration (poor body condition), they will not copulate that year. (4) There is no feeding outside of the foraging grounds. (5) Females can overwinter somewhere other than the breeding lagoons. (6) Female gray whales will prioritize resource allocation to their own survival and maintenance (metabolic rate) over calf maintenance and growth (lactation), and the latter over fetus maintenance and growth (pregnancy). (7) Females forage the maximum number of days possible given their reproductive state. (8) Females are capable of acquiring energy at the same rate during all foraging periods. For an extended description of the model assumptions, see the Supplement.

\section{Lost energy predictions}

Using the bioenergetics model, we predicted the consequences of lost energy, for both calving grounds, by making certain assumptions about what energetic conditions might result in the death of a calf or an adult female under 3 possible reproductive condi- tions. Each scenario was based on a $2+$ yr reproductive cycle with different energy acquisition and allocation requirements (based on the different reproductive conditions) (Fig. 2). Given that females are unable to be pregnant and lactate simultaneously, the 3 possible reproductive conditions when females are at the foraging grounds acquiring energy are: (A) pregnant, (B) non-pregnant and without a calf (resting), and (C) non-pregnant and with a calf (lactating). We calculated the proportion of lost energy that would have the following consequences on the females' reproduction and survival: (a) wean the calf at a lower mass, (b) lose the fetus (not produce a calf), but become pregnant and calve the following year, (c) neither produce a calf nor become pregnant, and therefore not calve the following year, and lastly (d) die. These 3 different reproductive conditions produce different demographic consequences of lost energy. For details of these calculations, see the Supplement.

\section{Population model linking lost energy to reproduction and survival}

The results from the bioenergetics model can be used in population projections to estimate population size and structure in the face of lost energy over potentially long time horizons. As an example, we used results from the bioenergetics model of WGW breeding in BajaC to determine the effects of lost energy on the number of adult females, the mass of surviving females, the stable proportion of calves weaned at a lower mass, and the stable reproductive rate of surviving females. We built a female population model using individual caloric requirements for reproduction and survival (bioenergetics model results) over a 100 yr period with a constant proportion of lost energy every year. We began by assigning a current reproductive state (pregnant, lactating, or resting) to 200 females by estimating the stable age distribution based on survival and reproductive rates (with uncertainty) from Cooke (2010). The probability of a female moving into 1 of the 3 reproductive conditions or dying the following summer was dependent on (1) current reproductive state (pregnant, lactating, or resting); (2) the amount of energy stored from previous cycles, (3) the amount of energy a female gains during a cycle, and (4) the energetic cost of transitioning to the new state.

We assumed no initial energy reserves and incremented the proportion of energy lost by 0.5 over the range 0.05 to 0.65 across all years, running the model 500 times per energy-lost increment, leading to 6500 
total runs. Initial adult female mass and costs of survival, migration, pregnancy, and lactation were a corresponding sample from the distributions created in the bioenergetics model. Since females were able to gain the same amount of energy every year, females either died the first year or survived the entire $100 \mathrm{yr}$, i.e. after the first year, survivors would never reach their mortality threshold under the current scenario. With consistently lower energy gain, reproductive output (including calf wean mass) of survivors becomes relatively stable, with some inter-annual variability that does not denote a changing temporal trend. We determined when the stability took place and calculated the stable reproductive rate and proportion of calves weaned at a lower mass by combining results of the 500 model runs at a given proportion of energy lost from years 40 through 100 . Therefore, uncertainty in stable results indicates variability both within and between simulation runs. For pseudo-code describing the simulation, see the Supplement.

\section{RESULTS}

\section{Gray whale female energetic demands}

When females spend the same amount of time in the breeding grounds, energy budgets are equivalent regardless of breeding ground location (BajaC or China). Therefore, subsequently we only present those results from WGW that remain in the China breeding grounds longer than WGW that migrate to
BajaC for comparative purposes. Thereafter, when referring to 'WGW breeding in China,' we are referring to the modeled scenario in which females' duration at the breeding grounds is longer than WGW breeding in BajaC. The comparisons also provide the range of potential energetic costs for WGW females breeding in China.

Total estimated energy (in $10^{4} \mathrm{MJ}$ ) for a 2 yr breeding cycle for a WGW female breeding in BajaC or China is 130.9 (66.9-213) and 136.2 (69.7-221.5), respectively. Minimum energy required to survive a year for these 2 breeding groups is 38 (15.8-66.6) and 41.1 (17.1-72.0), respectively (Tables 1 \& 2). Whichever breeding ground a pregnant female uses, she will require an average daily energy intake of 4.5 $(2.5-7.0) \times 10^{3} \mathrm{MJ} \mathrm{d}^{-1}$ on the foraging grounds (192 or $197 \mathrm{~d}$ ) in order to wean her calf successfully the next year. The daily energy intake (in $10^{3} \mathrm{MJ} \mathrm{d}^{-1}$ ) required on the foraging grounds for a year in which she arrives nursing a calf (successfully weaning her calf, assuming she acquired all the energy necessary for lactation the previous year) is 3.4 (1.4-5.9) (134 d at the foraging grounds) for females breeding in BajaC, and 3.3 (1.3-5.7) (148 d at the foraging grounds) for the South China Sea. For a year where she arrives at the feeding grounds neither pregnant nor with a calf (successfully breeding in subsequent year) she would have to consume 3.1 (1.3-5.5) (192 or $197 \mathrm{~d}$ at the foraging grounds) for each of the breeding locations. The estimated overall daily metabolic rate for the entire $2 \mathrm{yr}$ cycle is $1.5(0.62-2.6)$, and total pregnancy costs are $8.7(3.7-6.1) \times 10^{4} \mathrm{MJ}$ for each of the breeding grounds. Pregnancy costs are lower

Table 2. Energy requirements of western (WGW) and eastern (EGW) gray whales Eschrichtius robustus for different life stages, pregnancy, lactation, and daily metabolic rate; and \% increase in energy required in WGW compared to EGW, for 2 possible breeding grounds in Baja California (BajaC) and China. Data for EGW are from Villegas-Amtmann et al. (2015). Numbers in parentheses are the calculated 95\% credible intervals; na: not assessed

\begin{tabular}{|c|c|c|c|c|c|}
\hline \multirow[t]{2}{*}{ Energy requirements } & \multirow[t]{2}{*}{$\begin{array}{l}\text { WGW breeding } \\
\text { in BajaC }\end{array}$} & \multirow[t]{2}{*}{$\begin{array}{l}\text { WGW breeding } \\
\text { in China }\end{array}$} & \multirow[t]{2}{*}{ EGW } & \multicolumn{2}{|c|}{$\begin{array}{l}\text { \% increase in WGW } \\
\text { compared to EGW }\end{array}$} \\
\hline & & & & BajaC & China \\
\hline Total for a 2 yr breeding cycle $\left(\times 10^{4} \mathrm{MJ}\right)$ & $130.9(66.9,213)$ & $136.2(69.7,221.5)$ & $118.2(61.3,191.2)$ & 10.7 & 15.2 \\
\hline Total for 1 yr without calf (pregnant) $\left(\times 10^{4} \mathrm{MJ}\right)$ & $85.7(47.5,134.3)$ & $87.9(49.2,137.4)$ & $78.6(44.5,122.2)$ & 9 & 11.8 \\
\hline Total for 1 yr with calf $\left(\times 10^{4} \mathrm{MJ}\right)$ & $45.2(18.8,79.1)$ & $48.3(20.1,84.6)$ & $39.5(16.5,69.3)$ & 14.4 & 22.3 \\
\hline Total for $1 \mathrm{yr}$ without calf (not pregnant) $\left(\times 10^{4} \mathrm{MJ}\right)$ & $60.6(6.0,25.3)$ & $61.6(6.1,25.8)$ & na & na & na \\
\hline $\begin{array}{l}\text { Minimum to survive } 1 \mathrm{yr} \text { without calf } \\
\text { (pregnant or not) }\left(\times 10^{4} \mathrm{MJ}\right)\end{array}$ & $53.4(22.3,93.5)$ & $54.4(22.7,95.3)$ & $48.4(20.2,84.9)$ & 10.3 & 12.4 \\
\hline Minimum to survive $1 \mathrm{yr}$ with calf $\left(\times 10^{4} \mathrm{MJ}\right)$ & $38(15.8,66.6)$ & $41.1(17.1,72.0)$ & $35(14.6,61.3)$ & 8.6 & 17.4 \\
\hline Daily metabolic rate $\left(\times 10^{3} \mathrm{MJ} \mathrm{d}^{-1}\right)$ & $1.5(0.62,2.6)$ & $1.5(0.6,2.7)$ & $1.3(0.55,2.3)$ & 15.4 & 15.4 \\
\hline Pregnancy $\left(\times 10^{4} \mathrm{MJ}\right)$ & $8.7(3.7,16.1)$ & $8.7(3.7,16.1)$ & $8.7(3.7,16.2)$ & 0 & 0.0 \\
\hline Lactation $\left(\times 10^{4} \mathrm{MJ}\right)$ & $13.5(8.8,20.0)$ & $14.5(9.6,21.2)$ & $13.3(9.0,18.7)$ & 1.5 & 9.0 \\
\hline Migration (north and south) $\left(\times 10^{4} \mathrm{MJ}\right)$ & $25.5(10.6,44.8)$ & $14.2(5.9,24.9)$ & $19.6(8.2,34.3)$ & 30.1 & -27.6 \\
\hline Foraging grounds $\left(\times 10^{4} \mathrm{MJ}\right)$ & $73(30.4,127.8)$ & $77.6(32.3,135.9)$ & $62.1(25.9,108.7)$ & 17.5 & 25.0 \\
\hline
\end{tabular}


than total lactation costs, and these are $7 \%$ lower for the BajaC group (13.5 [8.8-20.0] × 104 MJ) than for the China breeding group (14.5 [9.6-21.2] × $\left.10^{4} \mathrm{MJ}\right)$ when females spend their extra time in the breeding grounds (Table 2), but would be the same as the BajaC group if the females spent their extra time in transit.

\section{Model disturbance predictions: consequences of lost foraging opportunities}

Reproductive condition A: pregnant

Given the assumptions and level of uncertainty in our model, the results are effectively the same for females breeding in BajaC or off China. Adult females would have insufficient energy to support minimum lactation costs for 5.4 or 5.3 mo (calf age when mother and calf arrive at foraging grounds, respectively) if BajaC females experienced a 3.1\% (1.6-5.4\%) reduction in net energy intake and if females breeding in China incurred a $3.3 \%$ (1.7$5.7 \%$ ) loss in net energy intake during their pregnancy phase. Consequently, based on our model assumptions, a female will not produce a calf that season, store any additional energy for reproduction the following year, and potentially become pregnant again at the breeding grounds; in this case, a female will enter a $3 \mathrm{yr}$ breeding cycle. If a BajaC or China breeding female experiences a $30.7 \%$ (18.9-49.1\%) and a $31.4 \%(19.5-49.7 \%)$ reduction in net foraging energy, respectively, during this period, she will not only lose her calf (pregnancy), but she will not be able to become pregnant the following breeding season (not enough energy to migrate), resulting in a 4 yr breeding cycle. Lastly, females from the BajaC or China breeding grounds would not be able to survive the winter non-feeding period if there were a $39.9 \%(28.5-55.1 \%)$ and $39.4 \%$ (28.8$55.6 \%$ ) reduction in energy intake during this phase of their reproductive cycle. This assumes that the female has no extra energy stores to compensate for a decrease in energy intake (Fig. 3, panels labeled IA and IIA).

\section{Reproductive condition B: resting}

As above, our model predicts that the energetic requirements of females breeding in BajaC are comparable to those breeding off China. To transition to a

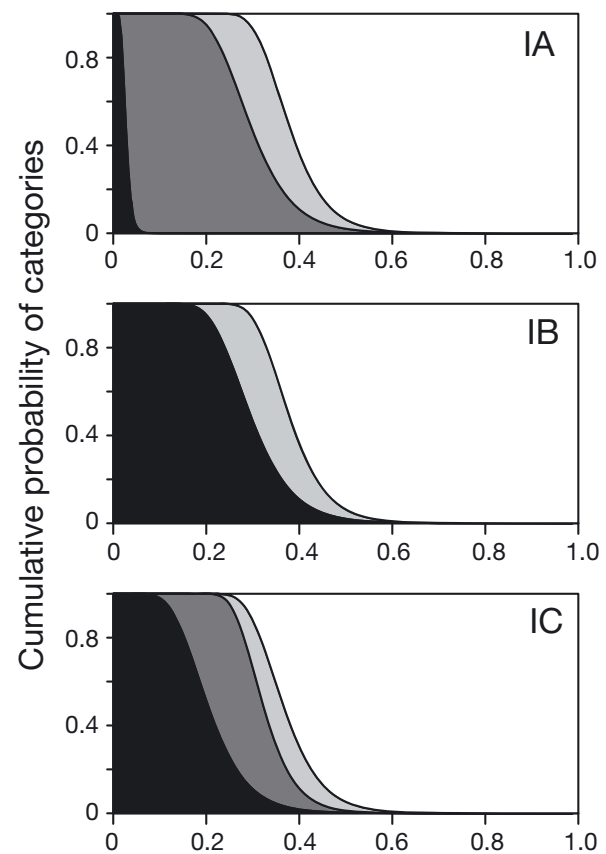

Female survives, gives birth, calf survives to feeding grounds

Female survives, aborts, breeds again

Female survives, aborts, does not breed again

$\square$ Female dies

Female survives and breeds

Female survives, does not breed

Female dies
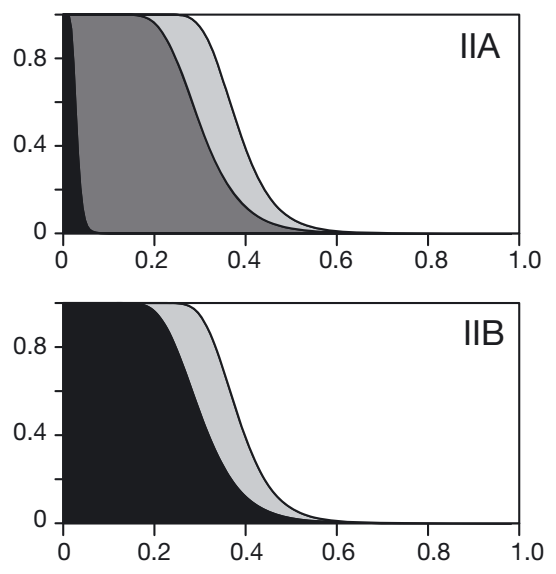

Female survives, breeds, normal calf wean mass

Female survives, does not breed, normal calf wean mass

$\square$ Female survives, does not breed, lower calf wean mass

$\square$ Female dies

\section{Fraction of energy lost}

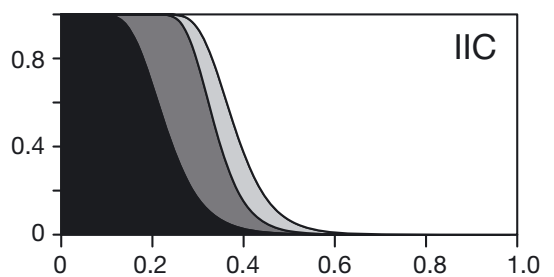

Fig. 3. Cumulative probabilities of female western gray whales Eschrichtius robustus falling into different categories depending on the fraction of energy lost, under 3 reproductive conditions: A, Pregnant, B, Resting (3+ yr reproductive cycle; this reproductive condition assumes that during the previous cycle a female did not have enough energy to sustain pregnancy or to migrate and become pregnant), and C, Lactating. IA-C females breeding in Baja California and IIA-C females hypothetically 
resting reproductive state, an animal can be in any reproductive condition: pregnant but cannot carry the pregnancy, resting with not enough energy for reproduction, or lactating and not enough energy for the next pregnancy. Under this resting scenario, a foraging energy reduction of $30.7 \%(18.9-49.1 \%)$ for the females breeding in BajaC, and 31.4\% (19.5$49.7 \%$ ) for the females breeding in China, during this phase, will prevent them from becoming pregnant the following breeding season. In this case, females will forgo an additional year of reproduction. Furthermore, these females will not likely survive once energetic losses exceed $39.9 \%(28.5-55.1 \%)$ and $39.4 \%(28.8-55.6 \%)$, respectively, of the net energy they can acquire during this non-pregnant/no-calf foraging period (Fig. 3, panels IB and IIB). Our predictions assume that the resting female has no extra energy stores to compensate for a decrease in energy intake.

\section{Reproductive condition C: lactating}

The model accounts for the possibility that a female may not have enough energy stored to complete lactation but successfully brings her calf to the foraging grounds (when the calf is 5.4 or $5.3 \mathrm{mo}$ old). Therefore, she must acquire additional energy for lactation while at the foraging grounds to nurse her calf until 6.6 or 6.5 mo old. Based on the assumptions from our bioenergetics model, a female will provision her existing calf before storing additional energy for future reproduction. In this situation, the assumption that females breeding off China spend the extra time in the breeding lagoon starts to affect the model output given that lactation costs will be higher. As previously mentioned, a female that spends the extra time in migration will have the same result as a female breeding in BajaC. Thus, a female will wean her calf at a normal mass but will not be able to migrate and breed (forgoing a year of breeding) if she loses $21.5 \%$ (10.6-38.3\%, BajaC females) and $24.0 \%(13.4-40.5 \%$, China females) of the energy she can acquire while foraging during this period. After having lost the ability to breed, a female is likely to wean her calf at a lower mass when energetic loss is $33.2 \%$ (24.3$47.0 \%)$ and $34.7 \%(25.8-48.4 \%)$, respectively. A female is not likely to survive once energetic losses exceed $37.7 \% \quad(27.0-54.2 \%)$ and $39.1 \% \quad(28.5-$ $55.3 \%)$, respectively, of the total energy she can acquire during this period (Fig. 3, panels IC and IIC).

\section{EGW and WGW comparison}

Mean energy requirements for the year in which a female is pregnant and for the year in which a female is lactating, were 9 and $14 \%$, and 12 and $22 \%$ greater for the WGW population breeding in BajaC and China, respectively, compared to the EGW population. The minimum amount of energy a WGW female breeding in BajaC and China would need to survive, for the year in which she is pregnant or without a calf, increases by 10 to $12 \%$ compared to EGW. The minimum amount of energy that a WGW female would need to survive, for the year in which she is lactating, is $9 \%$ greater for the BajaC breeding group and $17 \%$ greater for the China breeding group than an eastern female. Mean daily metabolic rate was $15 \%$ greater for the western population (from both breeding sites) compared to the eastern population. Mean lactation costs were only $2 \%$ greater for the western population breeding in $\mathrm{BajaC}$ and $9 \%$ greater for the population breeding in China, compared to the eastern population, and pregnancy costs were equal for all groups (Table 2, Fig. 4). Our model predicts that mortality would occur at $40-42 \%$ annual energetic loss for an eastern female and at $38-40 \%$ for a WGW female breeding in BajaC or in China.

\section{Population model linking lost energy to reproduction and survival}

Results from the female population model, based on the results from the reproductive model for the BajaC breeding ground, show that adult female survival begins to decline when females lose $30 \%$ of their energy in the first year, assuming that animals have no energetic reserves at the beginning of the simulation. Our model predicts that $50 \%$ of the females die in the first year when $42 \%$ of the energy is lost (Fig. 5A). When adult female survival probability falls to $<1$ during the first year, the surviving females are represented by smaller animals that can tolerate reduced energy conditions, since their own maintenance requirements are a lower proportion of total energy (Fig. 5B). These surviving females eventually reach a stable population-level reproductive rate, although inter-annual reproductive patterns may occur due to synchronous breeding, leading to high variability in reproductive rates for lost energy proportions below 0.2 (Fig. 5C). At low lost energy proportions, the first year of lost energy moves a higher proportion of females into the resting category. Those females are then able to accrue energy over 


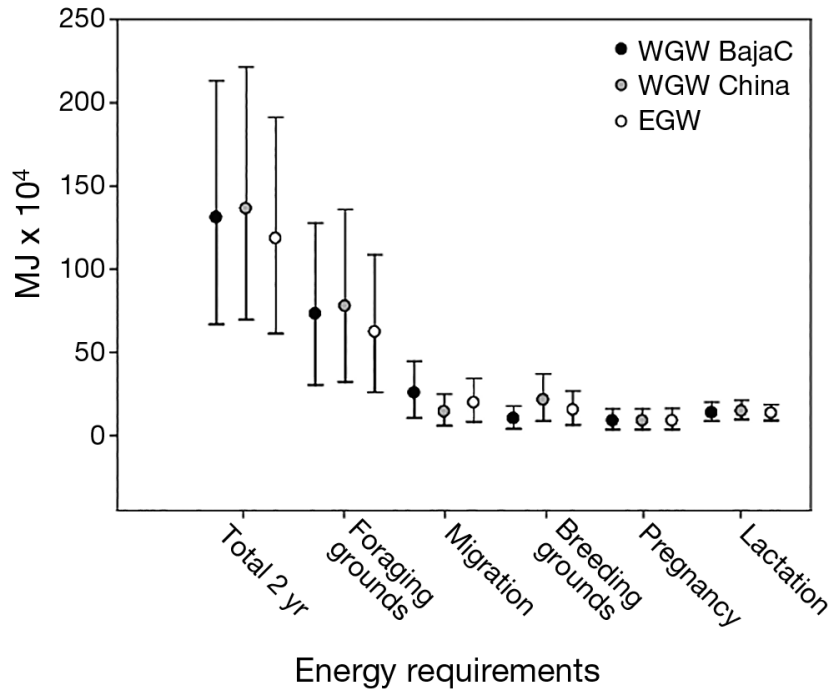

Fig. 4. Total energy requirements for a 2 yr breeding cycle with calculated $95 \%$ credible intervals and for the different life stages of eastern (EGW) and western gray whales (WGW) Eschrichtius robustus breeding in Baja California (BajaC) and a hypothetical location in China
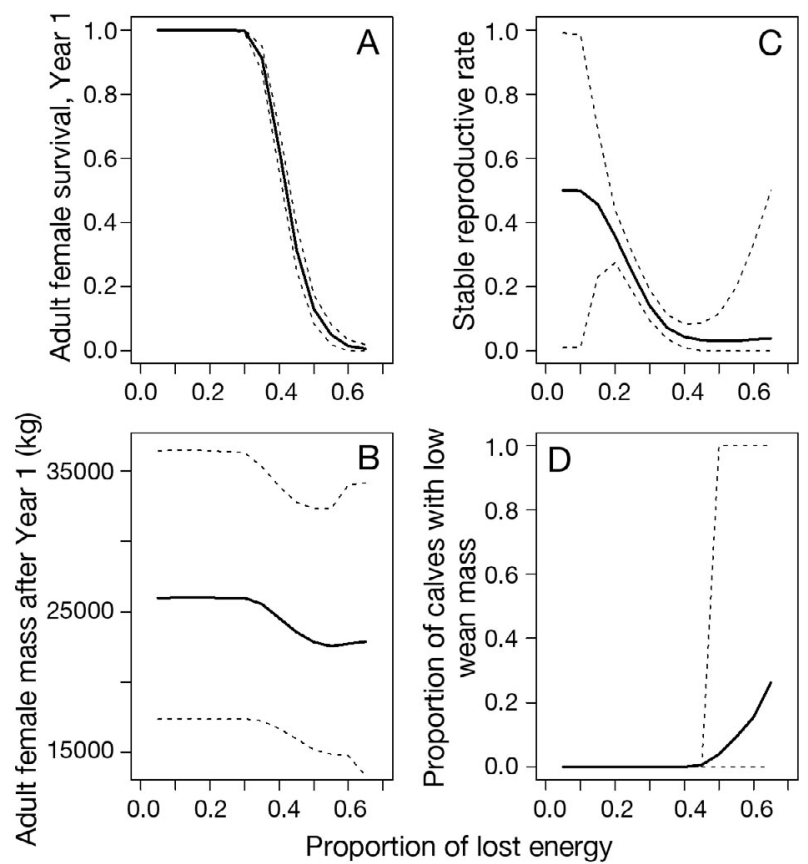

Fig. 5. Female western gray whale Eschrichtius robustus simulation of survival and reproduction with constant proportion of energy lost every year. Solid lines are means and dashed lines are $95 \%$ posterior intervals

1 or more years at the same rate. Therefore, variability includes years when many, if not all, females are either resting or breeding at the same time. When females consistently face a $42 \%$ or greater reduction in energy, the calf mass at weaning starts to decline (Fig. 5D). Uncertainty in both the proportion of calves with low wean mass and the reproductive rate increases as energy losses increase, because the proportion of surviving females is low. Likewise, the number of calves born to the small population of females is low. The resulting smaller sample size leads to lower resolution in the rates.

\section{DISCUSSION}

We have estimated WGW female energy requirements for a 2+ yr reproductive cycle for females breeding in BajaC and in China, and we have determined the consequences of lost energy under 3 possible female reproductive stages. We determined the percentage of energy lost that would result in a female not producing a calf during a particular year (suspend pregnancy) (3\%), not being able to reproduce (BajaC: $21-31 \%$ and China: $24-31 \%$ ), weaning a calf at a lower mass (33 and $35 \%$, respectively), and ultimately adult female mortality (38-40\% and $39 \%$, respectively). Energy loss of $\geq 30 \%$ in a year resulted in reduced adult female survival. An ongoing energy loss of $>30 \% \mathrm{yr}^{-1}$, simulated over a $100 \mathrm{yr}$ period, results in adult female mortality the first year, followed by slower recovery due to lower reproductive rates of survivors.

Estimates of FMR (all values in $10^{3} \mathrm{MJ} \mathrm{d}^{-1}$ ) from other studies and/or using other methods (Rice \& Wolman 1971: 1.6; Lockyer 1976: mean 1.3 [range: 0.9-1.7]; Sumich 1983: 1.2; Thomson \& Martin 1986: 1.3; Highsmith \& Coyle 1992: 2.2; Villegas-Amtmann et al. 2015: mean 1.3 [range 0.6-2.3]) fell within our quantified $95 \%$ credible intervals (mean: 1.5 [range: $0.62-2.6]$ ). The variance between this and other studies was mainly driven by differences in mass estimates, lung volumes, and breathing rates used.

\section{EGW and WGW comparison}

Comparing our results to EGW models (VillegasAmtmann et al. 2015), it appears that EGW can sustain higher energy losses than WGW, assuming EGW are using the historical migratory patterns. Female energy requirements, considering a $2 \mathrm{yr}$ breeding cycle, were greater for the western population. Total energy requirements (for a 2 yr breeding cycle) were on average $11 \%$ greater for the western population breeding in BajaC than the eastern one, due to the $25 \%$ increase in their migration length and their higher metabolic rate when they are pregnant (single females) at the foraging grounds (Table 1). However, 
Table 3. Daily energy consumption requirements at the foraging grounds, for adult female western gray whales Eschrichtius robustus under different reproductive states, breeding at 2 possible sites (Baja California [BajaC] and China), when they feed $100 \%$ of the time or $59 \%$ (Sychenko 2011) of the time at the foraging grounds. Numbers in parentheses are the calculated $95 \%$ credible intervals

\begin{tabular}{|c|c|c|c|c|c|c|c|c|}
\hline \multirow[t]{3}{*}{ Reproductive state } & \multicolumn{4}{|c|}{ - Daily energy requirements $\left(\times 10^{3} \mathrm{MJ} \mathrm{d}^{-1}\right)$} & \multirow{2}{*}{\multicolumn{2}{|c|}{$\begin{array}{c}\% \text { increase } \\
\text { at } 59 \%\end{array}$}} & \multirow{2}{*}{\multicolumn{2}{|c|}{$\begin{array}{c}\text { Foraging seasor } \\
\text { duration (d) }\end{array}$}} \\
\hline & At 1 & $0 \%$ & At 5 & $9 \%$ & & & & \\
\hline & BajaC & China & BajaC & China & BajaC & China & BajaC & China \\
\hline Pregnant & $4.5(2.5,7.0)$ & $4.5(2.5,7.0)$ & $7.6(4.2,11.8)$ & $7.6(4.2,11.8)$ & 68.9 & 68.9 & 192 & 197 \\
\hline With calf & $3.4(1.4,5.9)$ & $3.3(1.4,5.7)$ & $5.7(2.4,10.0)$ & $5.5(2.3,9.7)$ & 67.6 & 66.7 & 134 & 148 \\
\hline Non-pregnant, without calf & $3.1(1.3,5.5)$ & $3.1(1.3,5.5)$ & $5.4(2.2,9.4)$ & $5.3(2.2,9.3)$ & 74.2 & 71 & 192 & 197 \\
\hline
\end{tabular}

credible intervals indicate a large amount of overlap in final estimates.

In addition, breathing rates available to calculate metabolic rate at the foraging grounds for the EGW population did not differentiate between single females and females with calves. Breathing rates from eastern and WGW females with calves at the foraging grounds are comparable. However, for the WGW population, breathing rates for single females are higher than for females with calves, which is indicative of an increase in metabolic costs for this particular group of females (O. Sychenko unpublished; Table 1).

Since no data are available for the timing and energetics of females that may breed off China, we relied on data from both WGW and EGW that breed in BajaC (assuming that not all animals that forage around Sakhalin Island and migrate to BajaC to breed belong to the expanding EGW population [Mate et al. 2015] and some WGW do indeed migrate to BajaC to breed). Total energy requirements (for a 2 yr breeding cycle) for the WGW population breeding in China were on average $15 \%$ greater than the eastern population. This is intuitively contradictory given that the hypothesized breeding grounds in China are located significantly closer to the foraging grounds off Sakhalin Island, compared to breeding grounds in the BajaC lagoons. However, the whales cannot take advantage of a longer foraging season (increase energy input) by reducing their migration time, because ice limits the whales' access to their foraging grounds. Therefore, to compensate for a shorter migration in our model, we assumed females spent a longer time at the breeding grounds in China (3.4 vs. $2.1 \mathrm{mo}$ ). A greater percentage of lactation time spent at breeding grounds increases overall energy requirements. Calf breathing rates at the breeding grounds, used to determine metabolic costs, are higher than when they are migrating north (Table 1). Migration costs, however, are considerably smaller because the distance traveled is comparably short. Therefore, the increase in total energy require- ments for WGW breeding in China is due to higher metabolic rates at the foraging grounds (see above) and higher costs for lactation (calf FMR + calf growth costs) and at the breeding lagoons (Table 3). Nevertheless, this is purely hypothetical, as the 'western counterpart of the California gray whale' is thought to be extinct since the 1930s (Bowen 1974, p. 208).

The longer migration for WGW breeding in BajaC leads to a slightly shorter foraging period than for WGW breeding in China (192 vs. 197 d). Wean date is based on the number of days since arrival at the foraging grounds, and because WGW breeding in China arrive earlier, their lactation duration is slightly shorter (6.5 vs. $6.6 \mathrm{mo}$ ).

In contrast, if we assume females spend the same amount of time at the breeding grounds in China as WGW breeding in BajaC and migrate at a much slower rate, their total energy requirements would be lower and equal to those of WGW breeding in BajaC. However, behavioral strategies that promote energy optimization in social mammals and the selective forces acting on them may differ during different life history stages. Although it may be more energetically costly, spending a longer time at the breeding grounds may provide an advantage to both female and calf. A greater calf body size by the end of the breeding season may increase a calf's survival probability, reducing the risks of predation during the migration (Corkeron \& Connor 1999) and increasing swimming (Williams 1999, Cartwright \& Sullivan 2009) and foraging efficiency (Fortune et al. 2012). Lastly, a shorter migration distance and duration to the foraging grounds could possibly shorten the fraction of the lactation duration that relies solely on energy stores (fasting), allowing females to allocate a greater portion of their energy resources towards lactation.

Given our assumptions, and although the energetic costs associated with the 3 breeding grounds are comparable, it is more realistic to use the model output for WGW migrating to the BajaC breeding 
grounds. This seems to be the more energetically demanding scenario and has model input parameters collected from this particular migrating group.

If a substantial number of the females that forage off Sakhalin (WGW) do indeed migrate to BajaC to breed, the western population that breeds in BajaC may be more sensitive to disturbance compared to EGW if they cannot compensate for the additional energy needed for a longer migration. Although some data suggest a fully western migratory route for some animals, this seems plausible, as we have yet to identify a contemporary western breeding ground (Weller et al. 2002, 2012). Both eastern- and western-foraging females that breed in BajaC appear to be spending similar amounts of energy with regards to reproduction (pregnancy and lactation) given that lactation costs were only $1.5 \%$ greater for the longer-migrating western whales. To compensate for an increased energetic cost due to a longer migration, and to maintain similar reproductive energetic investment, we assumed that WGW might wean their calves a little earlier (6.6 mo) compared to EGW (7 mo).

In order to estimate the energetic costs for EGW, we assumed that animals feed in and around the Bering Strait and Chukchi Sea. However, EGW are regularly seen migrating farther north, and there is some indication that prey resources, particularly in the traditional foraging grounds we used, are no longer as abundant as they once were (Moore et al. 2003). If this trend continues and the majority of EGW migrate farther or have larger foraging ranges, the energetic costs for EGW and WGW breeding in BajaC will be very similar.

\section{Limitations of the bioenergetics model}

While our model provides some predictions regarding the possible consequences of lost foraging opportunities and potential differences in the sensitivity of different gray whale populations to disturbance, it also provides information about important data gaps and can help prioritize future research and mitigation efforts. For example, information on the existence and location of a breeding ground in China, the timing and pattern of its utilization, and the metabolic costs while there, are critical to developing a bioenergetics model for gray whales that may breed in China, as data on the timing and cost of migration will alter bioenergetics model outputs and predictions. Additional analyses will be needed to determine how disturbance affects energy intake. Those efforts will need to address how the gray whale's foraging behav- ior could change in response to disturbance, whether they can compensate by increasing foraging effort, how much energy is lost for a given level or type of disturbance, and potential changes in food availability and/or quality over the season.

One of our model assumptions is that females must procure all of the necessary energy for lactation and most energy for pregnancy during the year in which they are pregnant, based on the observation that calf production (as indicated by northbound calf counts) is most correlated with environmental fluctuations occurring in the foraging grounds during the year of calf production (Perryman et al. 2002a,b). Our model was built upon estimating the maximum energetic costs for a gray whale in a given year, that is, a female's reproductive costs, because their maximum energy acquisition capability is currently unknown. For this reason, it was not possible to set a maximum energy acquisition limit for a female during a foraging period beyond that of our estimated reproductive costs for a 2 yr breeding cycle (including migration, pregnancy, and lactation), which is in fact quite high per se. However, relaxing this assumption and increasing the amount of energy a female is able to acquire in a single foraging period would result in females being able to tolerate more disturbance before it had any effect on the probability of producing a calf. In this case, females are more likely to produce a calf at the maximum rate, i.e. every 2 yr. However, this is not what is currently observed in the population (Sychenko 2011, Cooke et al. 2013). Alternatively, it is likely that females are able to partition the cost of reproduction over multiple years, which is observed in the population inter-birth interval of 3 or more years (Sychenko 2011). Therefore, our model prediction of a $3 \%$ reduction in energy intake that would prevent a female from producing a calf that year, rather than suggesting reproductive failure, represents a reproductive amortization scenario, which is supported by the current observed inter-birth interval in the population.

\section{Compensating for lost foraging opportunities}

Our estimate of daily energy intake was calculated by dividing the total annual energy required for a given stage by the total number of days spent at the foraging grounds. While the calculation provides an overall average intake estimate, it does not account for variation in energy intake as a result of spatio-temporal variability in prey quality and quantity. Sychenko (2011) reported that WGW forage (including feeding/ 
traveling, feeding, and mixed behaviors) between 46 and $59 \%$ of their time at the foraging grounds. Therefore, if we consider that WGW feed a conservative $59 \%$ of the time while on the foraging grounds (which includes different behaviors, such as searching for food), they should be capable of increasing their foraging effort somewhat to compensate for disturbance. We estimated how energy input would change if a gray whale fed 100 or $59 \%$ of the time in Table 3 . When females only forage for $59 \%$ of the time, energy consumption rates or feeding intensity increase by $69 \%$ when females arrive pregnant from both breeding sites, by 68 and $67 \%$ when females arrive with a calf, and by 74 and $71 \%$ when females arrive non-pregnant and without a calf from BajaC and China breeding grounds, respectively (Table 3).

Knowledge of the timing and rate of energy intake during foraging would be quite beneficial in developing appropriate mitigation strategies. For example, disturbances could be limited to specific times of day or at the beginning, middle, or end of the foraging season. The current mitigation strategy is to try and avoid or reduce any interactions by conducting activities as early in the foraging season as possible before the gray whales arrive (Nowacek et al. 2013, Bröker et al. 2015). In addition, disturbance earlier in the season may allow exposed animals to compensate for lost foraging by increasing their foraging effort during non-disturbance periods later in the season. However, gray whales spend a greater percentage of their time foraging at the beginning than later in the feeding season when they are observed to be engaged in different behaviors such as traveling and socializing (Zimushko \& Ivashin 1980, Gailey et al. 2008). It is likely that upon arrival at the foraging grounds, whales would prioritize foraging as they will be in an emaciated condition, eager to feed, and as their body stores are replenished, they could spend more time engaged in other activities. Alternatively, disturbance later in the season may not have as great an impact on their energy requirements, when the whales appear to spend more time in activities not associated with foraging. However, some of the nonforaging time may include important periods when whales are socializing, milling, and/or traveling, and it is unclear how these activities might be affected by disturbance. If disturbance is spatially limited compared to the entire foraging area, whales may also alleviate some of the energy lost by moving to other regions within the foraging area, or to a secondary feeding ground.

Based on EGW, as pregnant females are the first to arrive and first to leave the foraging grounds (Pike
1962, Rice \& Wolman 1971, Sumich 1986), disturbance at the beginning of the feeding season may place them at greater risk. Furthermore, pregnant females have the greatest energy requirements, and they are under a greater time constraint to return to the breeding grounds. Mitigation strategies targeted at mother-calf pairs are useful, but it should also be considered that these individuals occur closer to shore and therefore are usually farther from the industrial activity that generally occurs near the feeding grounds (Sychenko 2011). In addition, disturbance at the end of the feeding season may be less harmful to mother-calf pairs. It would minimize disturbance during the last portion of lactation (which occurs at the beginning of the feeding season), and calves would likely be weaned prior to the disturbance, reducing the energetic demands on females.

Regardless of the time when disturbance might occur, there is evidence that anthropogenic disturbance may affect gray whale foraging behavior. A reduction in feeding appears to occur, as WGW have been observed to travel faster in a more directed path when exposed to high levels of sound from seismic surveys. Additionally, they were distributed farther from shore, and stayed under water longer between respirations (Gailey et al. 2007, 2010). Even though mitigation measures during seismic surveys have been implemented recently, sample sizes were small; therefore, it is difficult to assess their effectiveness in minimizing behavioral responses of WGW to vessel proximity and sound (Gailey et al. 2016, Muir et al. 2016).

While this study is limited to the reproductive and survival outcomes of reduced energy, further analyses of behavioral data will determine how, or if, gray whales are able to compensate for lost foraging time during different periods within the foraging season. Stochastic dynamic programming (SDP) will aid in estimating how far gray whales deviate from optimal foraging strategies in the face of disturbance (Mangel \& Clark 1988, Clark \& Mangel 2000). The next step in SDP disturbance modeling will require additional information on the prey and predator landscapes (Schwarz et al. 2016, McHuron et al. 2017). Together, these research efforts would help establish the most effective mitigation strategy.

\section{Population model linking lost energy to reproduction and survival}

Low weaning mass does not appear in our model until more than $40 \%$ of annual energy has been lost. 
This occurs because a large proportion of adult females that would otherwise wean calves at a lower mass die in the first year, so they do not contribute to future calf wean mass. Also, females are likely to delay a future reproductive event to improve the success of the current one. That is, lower weaning mass only occurs with large energy losses because the surplus energy a female acquires while lactating at the foraging grounds will be used to provide for her current calf, for which she has already invested a substantial amount of energy, rather than to becoming pregnant the following year. Therefore, reproductive rates become quite low (near $3 \%$ ) before energy that can be used for reproduction decreases enough to also cause low calf weaning mass.

Our population model addresses questions about how lost energy could lead to smaller adult females, lower reproductive rates, and lower wean masses. However, we would need to address further questions about the remainder of the population to carry out a full population viability analysis:

(1) What would the metabolic needs of future adults be? In the population model, females that survive the first year of high energy loss are smaller, because smaller females require less energy and a lower proportion of their total energy needed for survival compared to larger females. Given that future generations originate from smaller mothers, would offspring adult body size also be smaller? This would lead to lower energetic needs for offspring, increasing their likelihood of survival during poor foraging periods. In addition, are offspring reproductive rate and reproductive costs the same as those of their mothers?

(2) What are the energetic costs of maturation, particularly if animals are growing during fasting?

(3) Is survival a function of weaning mass? In other words, do calves weaned at a lower wean mass have a lower probability of survival?

While we have investigated the consequences of lost energy purely from an energetics perspective, there may be other factors that could influence female survival as a consequence of energy loss, such as poor body condition, compromised immune response, and an increased risk of predation.

\section{Future implications}

Although our model focuses on the potential effects of lost foraging opportunities, it is also applicable for assessing disturbance costs or other effects associated with climate change and/or anthropogenic activities, along their migratory route or at the breeding grounds (such as whale watching). These could increase the females' energy expenditure, and without compensation of the energy consumed at the foraging grounds, would ultimately affect their energy budget allocation.

While our bioenergetics model provides insights into the potential costs of disturbance it could be made more robust if empirical data were available to support or refute a number of the assumptions we made. Information on the existence and location of any western breeding grounds for WGW, and on the amount of time that females use these grounds, is required before we could then be confident that these females actually do have higher reproductive costs than those breeding in BajaC. More information on the timing of arrival and departure of individual animals (EGW and WGW), their age, gender, and reproductive status would help to identify the energetic requirements of specific classes of animals, particularly because our estimates of the time spent on the breeding grounds are an average across many individuals of different status and arrival dates. We do not know whether animals that arrive early will also leave early and whether animals that arrive late will leave late. If animals spend less time at the foraging grounds, we would have underestimated their energy intake rates.

Information on the females' ability to compensate for the effects of disturbance is critical for our understanding of the effects of disturbance, and there are many gaps in our knowledge. We assume that any disturbance results in an energy deficit, but we do not know the form of this relationship. We do not know if it is an all-or-nothing response, or if the only cost, when animals move away from the source, is the time spent moving. In addition, we need information to elucidate whether animals continue to feed while disturbed, and if they do so at a reduced rate. Furthermore, examining chronic stress in animals that frequently feed during disturbance, and information on changes in the metabolic rates (breathing rates) of different age/sex classes, would improve our knowledge of the potential physiological consequences of disturbance. Finally, of equal importance is knowing how prey resources change over the season, and whether this change is due to gray whale foraging or the preys' own phenology. There is likely an effect of the patch quality on the cost of foraging in that patch, as feeding either shallow or deep might be more energetically costly. Fortunately, the methodology exists to answer many of these issues using a combination of empirical studies and modeling. 
Acknowledgements. This work was inspired by the Population Consequences of Disturbance (PCoD) working group funded by the Office of Naval Research. This work was part of the project 'Application of the PCAD model to the California gray whale, integration of existing data and towards a quantitative assessment of biological significance of acoustic disturbance,' jointly funded by research grants from ExxonMobil and the Shell Oil Foundation. The behavioral data that were used in this paper were funded by Exxon Neftegas Limited and Sakhalin Energy Investment Company. Special thanks to R. Melton and K. Bröker for reviewing and providing insightful comments for this manuscript.

\section{LITERATURE CITED}

Anderson SS, Fedak MA (1987) The energetics of sexual success of grey seals and comparison with the costs of reproduction in other pinnipeds. In: Loudon ASI, Racey PA (eds) Reproductive energetics in mammals. Oxford University Press, New York, NY, p 319-339

* Baker CS, Dalebout ML, Lento GM, Funahashi N (2002) Gray whale products sold in commercial markets along the Pacific coast of Japan. Mar Mamm Sci 18:295-300

Bickham JW, Dupont JM, Broker K (2013) Review of the status of the western North Pacific gray whale; stock structure hypotheses, and recommendations for methods of future genetic studies. Paper SC/65a/BRG16 presented to the IWC Scientific Committee, November 2013. https://www.researchgate.net/publication/271816140

Blaxter K (1989) Energy metabolism in animals and man. Cambridge University Press, Cambridge

Blokhin SA (1986) Investigations of gray whales taken off Chukotka in 1984. Rep Int Whaling Comm 36:287-290

Blokhin SA, Burdin AM (2001) Distribution, abundance and some traits of behavior of the gray whale Eschrichtius robustus of the Korean stock at the northeastern coast of Sakhalin. Biol Mora (Vladivost) 27:15-20

Bogoslovskaya LS, Votrogov LM, Semenova TM (1981) Feeding habits of the gray whales off the Chukotka Peninsula. Rep Int Whaling Comm 31:507-510

Bowen SL (1974) Probable extinction of the Korean stock of the gray whale (Eschrichtius robustus). J Mammal 55: 208-209

Brody S (1945) Bioenergetics and growth with special reference to the efficiency complex in domestic animals. Hafner Press, New York, NY

Bröker K, Gailey G, Muir J, Racca R (2015) Monitoring and impact mitigation during a $4 \mathrm{D}$ seismic survey near a population of gray whales off Sakhalin Island, Russia. Endang Species Res 28:187-208

Brownell RL Jr, Kasuya T (1999) Western gray whale captured off western Hokkaido, Japan. Paper SC/51/AS25 presented to the IWC Scientific Committee, May 1999. IWC Secretariat, Cambridge

Brownell RL Jr, Yablokov AV (2001) Endangered Sakhalin gray whales face cumulative threats on their feeding ground during summer 2001. Paper SC/53/BRG22 presented to the IWC Scientific Committee, July 2001. IWC Secretariat, Cambridge

Cartwright R, Sullivan M (2009) Associations with multiple male groups increase the energy expenditure of humpback whale (Megaptera novaeangliae) female and calf pairs on the breeding grounds. Behaviour 146: 1573-1600
Clark CW, Mangel M (2000) Dynamic state variable models in ecology: methods and applications. Oxford University Press, New York, NY

* Cooke J (2010) Joint population assessment of western gray whales using data from IBM and Russia-US photo-identification teams collected off Sakhalin Island through 2008. Paper WGWAP 8/09 presented at the 8th Meeting of the Western Gray Whale Advisory Panel. IUCN, Geneva. http://cmsdata.iucn.org/downloads/wgwap_8_doc_09_ joint_population_assessment.pdf

Cooke JG, Weller DW, Bradford AL, Sychenko O, Burdin AM, Brownell RLJ (2013) Population assessment of Sakhalin gray whale aggregation. Paper SC/65a/BRG27 presented to the IWC Scientific Committee, 2013. IWC Secretariat, Cambridge

Cooke JG, Weller DW, Bradford AL, Sychenko O, Burdin AM, Lang AR, Brownell RL Jr (2015) Updated population assessment of the Sakhalin gray whale aggregation based on the Russia-US photoidentification study at Piltun, Sakhalin, 1994-2014. Paper WGWAP/16/17 presented at the Western Gray Whale Advisory Panel, 16th Meeting. http://cmsdata.iucn.org/downloads/wgwap_16___17_ cooke_et_al.pdf

* Corkeron PJ, Connor RC (1999) Why do baleen whales migrate? Mar Mamm Sci 15:1228-1245

Costa DP (2009) Energetics. In: Perrin WF, Thewissen JGM, Würsig B (eds) Encyclopedia of marine mammals. Academic Press, San Diego, CA, p 791-796

Costa DP (2012) A bioenergetics approach to developing the PCAD model. In: Popper AN, Hawkins A (eds) The effects of noise on aquatic life. Advances in experimental medicine and biology. Springer Science and Business Media, New York, NY, p 423-426

Costa DP, Leboeuf BJ, Huntley AC, Ortiz CL (1986) The energetics of lactation in the northern elephant seal, Mirounga angustirostris. J Zool 209:21-33

* Demchenko NL, Chapman JW, Durkina VB, Fadeev VI (2016) Life history and production of the western gray whale's prey, Ampelisca eschrichtii Kroyer, 1842 (Amphipoda, Ampeliscidae). PLOS ONE 11:e0147304

Fadeev VI (2004) Benthos and food supply studies in feeding grounds of the Okhotsk-Korean gray whale population. Final report. On materials from field studies on the seagoing tug Nevelskoy in 2001. Marine Biology Institute of the Far East Branch of the Russian Academy of Sciences, Vladivostok

Fadeev VI (2008) Benthos studies in feeding grounds of the Okhotsk-Korean gray whale population in 2007. Report for the Marine Biology Institute of the Far East Branch of the Russian Academy of Sciences, Vladivostok

Fortune SME, Trites AW, Perryman WL, Moore MJ, Pettis HM, Lynn MS (2012) Growth and rapid early development of North Atlantic right whales (Eubalaena glacialis). J Mammal 93:1342-1354

* Gailey G, Würsig B, McDonald TL (2007) Abundance, behavior, and movement patterns of western gray whales in relation to a 3-D seismic survey, Northeast Sakhalin Island, Russia. Environ Monit Assess 134:75-91

* Gailey GO, Sychenko O, Würsig B (2008) Patterns of western gray whale behavior, movement and occurrence off Sakhalin Island, 2007. Prepared for LGL Ecological Research Associates Ltd. for Exxon-Neftegas Ltd. and Sakhalin Energy Investment Company, YuzhnoSakhalinsk. www.sakhalinenergy.com/media/2a760f68ea52-4d66-a1cd-5951c7c4f88f.pdf 
Gailey G, McDonald T, Racca R, Sychenko O and others (2010) Western gray whale movement, respiration, and abundance during pipeline construction off Sakhalin Island, Russia. Prepared for Exxon-Neftegas Ltd. and Sakhalin Energy Investment Company, YuzhnoSakhalinsk

Gailey G, Sychenko O, McDonald T, Racca R, Rutenko A, Bröker K (2016) Behavioural responses of western gray whales to a 4-D seismic survey off northeastern Sakhalin Island, Russia. Endang Species Res 30:53-71

Hanwell A, Peaker M (1977) Physiological effects of lactation on the mother. Symp Zool Soc Lond 41:297-311

Harvey JT, Mate BR (1984) Dive characteristics and movements of radio-tagged gray whales in San Ignacio Lagoon, Baja California Sur, Mexico. In: Jones ML, Swartz SL (eds) The gray whale Eschrichtius robustus. Academic Press, Orlando, FL, p 561-575

Highsmith RC, Coyle KO (1992) Productivity of arctic amphipods relative to gray whale energy requirements. Mar Ecol Prog Ser 83:141-150

Jones ML, Swartz SL, Leatherwood S (1984) The gray whale Eschrichtius robustus. Academic Press, Orlando, FL

Kleiber M (1961) The fire of life: an introduction to animal energetics. Robert E. Krieger Publishing Company, Huntington, NY

Kurta A, Kunz TH (1987) Size of bats at birth and maternal investment during pregnancy. In: Loudon ASI, Racey PA (eds) Reproductive energetics in mammals. Oxford University Press, New York, NY

Laake J, Punt A, Hobbs R, Ferguson M, Rugh D, Breiwick J (2009) Re-analysis of gray whale southbound migration surveys 1967-2006. NOAA Tech Memo NMFS-AFSC203:55. NOAA, US Department of Commerce, Springfield, VA

Lang AR, Weller DW, LeDuc R, Burdin AM and others (2011) Genetic analysis of stock structure and movements of gray whales in the eastern and western North Pacific. Paper SC/63/BRG10 presented to the IWC Scientific Committee, May-June 2011. IWC Secretariat, Cambridge

LeDuc RG, Weller DW, Hyde J, Burdin AM and others (2002) Genetic differences between western and eastern gray whales (Eschrichtius robustus). J Cetacean Res Manag 4: $1-5$

Lockyer C (1976) Growth and energy budgets of large baleen whales from the Southern Hemisphere. Paper ACMRR/ MM/SC/41. FAO Scientific Consultation on Marine Mammals, Bergen

Mangel M, Clark CW (1988) Dynamic modeling in behavioral ecology. Princeton University Press, Princeton, NJ

Mate BR, Bradford AL, Tsidulko G, Vertyankin V, Ilyashenko V (2011) Late feeding season movements of western North Pacific gray whales off Sahkalin Island, Russia and subsequent migration into the eastern North Pacific. Paper SC/63/BRG23 presented to the IWC Scientific Committee, May-June 2011. IWC Secretariat, Cambridge

Mate BR, Ilyashenko VY, Bradford AL, Vertyankin VV, Tsidulko GA, Rozhnov VV, Irvine LM (2015) Critically endangered western gray whales migrate to the eastern North Pacific. Biol Lett 11:20150071

McHuron EA, Costa DP, Schwarz L, Mangel M (2017) Statedependent behavioural theory for assessing the fitness consequences of anthropogenic disturbance on capital and income breeders. Methods Ecol Evol 8:552-560

Moore SE, Grebmeier JM, Davies JR (2003) Gray whale distribution relative to forage habitat in the northern Bering
Sea: current conditions and retrospective summary. Can J Zool 81:734-742

"Muir JE, Ainsworth L, Racca R, Bychkov Y and others (2016) Gray whale densities during a seismic survey off Sakhalin Island, Russia. Endang Species Res 29:211-227

Nerini M (1984) A review of gray whale feeding ecology. In: Jones ML, Swartz SL, Leatherwood S (eds) The gray whale Eschrichtius robustus. Academic Press, New York, NY, p 423-448

New LF, Moretti DJ, Hooker SK, Costa DP, Simmons SE (2013) Using energetic models to investigate the survival and reproduction of beaked whales (family Ziphiidae). PLOS ONE 8:e68725

New LF, Clark JS, Costa DP, Fleishman E and others (2014) Using short-term measures of behaviour to estimate long-term fitness of southern elephant seals. Mar Ecol Prog Ser 496:99-108

Nowacek DP, Bröker K, Donovan G, Gailey G and others (2013) Responsible practices for minimizing and monitoring environmental impacts of marine seismic surveys with an emphasis on marine mammals. Aquat Mamm 39: 356-377

NRC (National Research Council) (2005) Marine mammal populations and ocean noise: determining when noise causes biologically significant effects. National Academies Press, Washington, DC

*Perryman WL, Donahue MA, Perkins PC, Reilly SB (2002a) Gray whale calf production 1994-2000: Are observed fluctuations related to changes in seasonal ice cover? Mar Mamm Sci 18:121-144

Perryman WL, Watters GM, Schwarz LK (2002b) Examination of the relationship between seasonal ice and calf production in the Eastern Pacific population of gray whales. Paper SC/54/BRG4 presented to the IWC Scientific Committee, 2002. IWC Secretariat, Cambridge

* Pike GC (1962) Migration and feeding of the gray whale (Eschrichtius gibbosus). J Fish Res Board Can 19:815-838

Punt AE, Wade PR (2010) Population status of the eastern North Pacific stock of gray whales in 2009. Tech Memo NMFS-AFSC 207. US Department of Commerce, NOAA, Springfield, VA

*Pyenson ND, Lindberg DR (2011) What happened to gray whales during the Pleistocene? The ecological impact of sea-level change on benthic feeding areas in the North Pacific Ocean. PLOS ONE 6:e21295

Reilly SB, Bannister JL, Best PB, Brown M and others (2008) Eschrichtius robustus. The IUCN Red List of Threatened Species 2008: e.T8097A12885255.en. www.iucnredlist.org/ details/8097/0

Rice DW, Wolman AA (1971) The life history and ecology of the gray whale (Eschrichtius robustus). Spec Publ 3. American Society of Mammalogists, Washington, DC

Rodriguez de la Gala-Hernandez S, Heckel G, Sumich JL (2008) Comparative swimming effort of migrating gray whales (Eschrichtius robustus) and calf cost of transport along Costa Azul, Baja California, Mexico. Can J Zool 86:307-313

Schwarz LK (2002) The impact of anthropogenic activities on the behavior of migrating eastern North Pacific gray whales (Eschrichtius robustus). Dissertation. San Diego State University, San Diego, CA, USA

Schwarz LK, McHuron E, Mangel M, Wells RS, Costa DP (2016) Stochastic dynamic programming: an approach for modeling the population consequences of disturbance due to lost foraging opportunities. Proceedings of 
Meetings on Acoustics, Vol 27. 4th International Conference on the Effects of Noise on Aquatic Life. Acoustical Society of America, p 1-9

Sumich JL (1983) Swimming velocities, breathing patterns, and estimated costs of locomotion in migrating gray whales, Eschrichtius robustus. Can J Zool 61:647-652

Sumich JL (1986) Latitudinal distribution, calf growth and metabolism, and reproductive energetics of gray whales, Eschrichtius robustus. PhD dissertation, Oregon State University, Corvallis, OR

Sychenko O (2011) Western gray whale (Eschrichtius robustus) mother and calf ecology off Sakhalin Island. MSc thesis, Texas A\&M University, College Station, TX

Thomson DH, Martin LR (1986) Feeding ecology of gray whales in the Chirikof Basin. In: Thomson DH (ed) Feeding ecology of gray whales (Eschrichtius robustus) in the Chirikof Basin, summer 1982. OCSEAP Final Report 43. US Department of Commerce, NOAA, Anchorage, AK, p 377-460

Tyurneva OY, Yakovlev YM, Vertyankin VV, Selin NI (2010) The peculiarities of foraging migrations of the KoreanOkhotsk gray whale (Eschrichtius robustus) population in Russian waters of the Far Eastern seas. Russ J Mar Biol 36:117-124

Villegas-Amtmann S, Schwarz LK, Sumich JL, Costa DP (2015) A bioenergetics model to evaluate demographic consequences of disturbance in marine mammals applied to gray whales. Ecosphere 6(10):183

Wang P (1984) Distribution of the gray whale Eschrichtius gibbosus off the coast of China. Acta Theriol Sin 4:21-26

Weller DW, Würsig B, Bradford AL, Burdin AM, Blokhin SA, Minakuchi H, Brownell RL Jr (1999) Gray whales (Eschrichtius robustus) off Sakhalin Island, Russia: seasonal and annual patterns of occurrence. Mar Mamm Sci 15: 1208-1227

Editorial responsibility: David Lusseau, Aberdeen, UK
Weller DW, Burdin AM, Würsig B, Taylor BL, Brownell RL Jr (2002) The western gray whale: a review of past exploitation, current status and potential threats. J Cetacean Res Manag 4:7-12

Weller DW, Bradford AL, Kato H, Bando T, Otani S, Burdin AM, Brownell RL Jr (2008a) A photographic match of a western gray whale between Sakhalin Island, Russia, and Honshu, Japan: the first link between the feeding ground and a migratory corridor. J Cetacean Res Manag 10:89-91

Weller DW, Bradford AL, Lang AR, Kim HW and others (2008b) Status of western gray whales off northeastern Sakhalin Island, Russia, in 2007. Paper SC/60/BRG3 presented to the IWC Scientific Committee, 2008. IWC Secretariat, Cambridge

*Weller DW, Klimek A, Bradford AL, Calambokidis J and others (2012) Movements of gray whales between the western and eastern North Pacific. Endang Species Res 18: 193-199

Williams TM (1999) The evolution of cost efficient swimming in marine mammals: limits to energetic optimization. Philos Trans R Soc Lond B 354:193-201

* Williams TM, Rutishauser M, Long B, Fink T, Gafney J, Mostman-Liwanag H, Casper D (2007) Seasonal variability in otariid energetics: implications for the effects of predators on localized prey resources. Physiol Biochem Zool 80:433-443

Zhu Q (1998) Strandings and sightings of the western Pacific stock of the gray whale Eschrichtius robustus in Chinese coastal waters. Paper SC/50/AS5 presented to the IWC Scientific Committee, April 1998. IWC Secretariat, Cambridge

Zimushko VV, Ivashin MV (1980) Some results of Soviet investigations and whaling of gray whales. Rep Int Whaling Comm 30:237-246

Submitted: August 7, 2016; Accepted: May 31, 2017 Proofs received from author(s): August 3, 2017 